\section{A Framework to Guide Undergraduate Education in Interdisciplinary Science}

\author{
Brie Tripp and Erin E. Shortlidge*
}

Department of Biology, Portland State University, Portland, OR 97201

\begin{abstract}
An expanded investment in interdisciplinary research has prompted greater demands to integrate knowledge across disciplinary boundaries. Vision and Change similarly made interdisciplinary expectations a key competency for undergraduate biology majors; however, we are not yet synchronized on the meaning of interdisciplinarity, making this benchmark difficult to meet and assess. Here, we discuss aspects of interdisciplinarity through a historical lens and address various institutional barriers to interdisciplinary work. In an effort to forge a unified path forward, we provide a working definition of interdisciplinary science derived from both the perspectives of science faculty members and scientific organizations. We leveraged the existing literature and our proposed definition to build a conceptual model for an Interdisciplinary Science Framework to be used as a guide for developing and assessing interdisciplinary efforts in undergraduate science education. We believe this will provide a foundation from which the community can develop learning outcomes, activities, and measurements to help students meet the Vision and Change core competency of "tapping into the interdisciplinary nature of science."
\end{abstract}

\section{INTRODUCTION}

Interdisciplinarity has evolved from a "buzzword" to a necessity, with several leading funding agencies (e.g., the National Science Foundation [NSF] and the National Institutes of Health) calling for shifts from predominantly disciplinary-focused research endeavors to interdisciplinary collaborations (Rosenfield, 1992; Stokols et al., 2005; Masse et al., 2008; President's Council of Advisors on Science and Technology [PCAST], 2012). These organizations have acknowledged that key issues facing our society increasingly require the integration of multiple disciplines to propose solutions to vital, complex problems like global climate change, loss of biodiversity, and epidemics of infectious disease (Stokols et al., 2008; Klein, 2015; You et al., 2018). On a smaller scale, the bridging of traditional disciplines has occurred to address complex research questions, often resulting in new fields of study such as chemical ecology, biomedical engineering, and sociobiology (Lattuca, 2001; Klein, 2015). These emerging fields of research open up new arenas where researchers think, act, and potentially teach beyond the scope of a single discipline (Repko, 2008; Boix Mansilla et al., 2009; Frodeman et al., 2017).

In alignment with funding agencies' initiatives, the NSF and the American Association for the Advancement of Science (AAAS) held a series of meetings that outlined a number of priorities, including the idea that higher education should be better preparing undergraduate biology students for an increasingly interdisciplinary scientific workforce. A report from these meetings, Vision and Change in Undergraduate Biology Education (AAAS, 2011), charged the community to equip undergraduate biology students with an improved skill set that includes harnessing six core competencies by the completion of their undergraduate degree. The ability to "tap into the interdisciplinary nature of science" is one of these competencies. This competency may be challenging to meet for a variety of reasons including 1) the historical prominence of siloed disciplines (Klein, 1990; Moran, 2002; Repko, 2008;
Jennifer Loertscher, Monitoring Editor Submitted Nov 21, 2018; Revised Mar 26, 2019; Accepted Mar 28, 2019

CBE Life Sci Educ June 1, 2019 18:es3 DOI:10.1187/cbe.18-11-0226

*Address correspondence to: Erin E. Shortlidge (eshortlidge(apdx.edu).

(c) 2019 B. Tripp and E. E. Shortlidge. CBE-Life Sciences Education ๑ 2019 The American Society for Cell Biology. This article is distributed by The American Society for Cell Biology under license from the author(s). It is available to the public under an Attribution-Noncommercial-Share Alike 3.0 Unported Creative Commons License (http://creativecommons.org/licenses/ by-nc-sa/3.0)

"ASCBß" and "The American Society for Cell Biology $\circledR^{\prime}$ are registered trademarks of The American Society for Cell Biology. 
Weingart, 2010), 2) institutional barriers that inhibit crosspollination of disciplines (Moran, 2002; Weingart, 2010; Scott et al., 2014), and 3) ambiguity and discord on a unified definition (Bennington, 1999; Lattuca and Knight, 2010). If institutions nationwide are charged with distilling this competency to undergraduates, we must first have a unified understanding of what the competency entails, the kinds of experiences an undergraduate student might feasibly gain in interdisciplinary science, what proficiency in this competency would look like, and how to measure those expected outcomes. Simply put, the problem of how to meet this competency and what to measure remains largely ambiguous.

In this essay, we provide an overview of the challenges that interdisciplinary studies have generally faced, address the current state of academic culture as it relates to interdisciplinarity, and summarize varying definitions of interdisciplinarity borrowed from the humanities and the sciences. We then provide a working definition of interdisciplinary science, derived from both the literature and our own research probing the expertise of more than 180 faculty members. We conclude by presenting an Interdisciplinary Science Framework (IDSF), curricula that align with the model, and an example of how to apply the IDSF to a science course as a launch point for practitioners to develop and/or assess instruction that fosters students' ability to tap into the interdisciplinary nature of science.

\section{HISTORY OF INTERDISCIPLINARITY}

The term "interdisciplinary" first surfaced in the early 20th century, being used by the Social Science Research Council as a bureaucratic shorthand for the promotion of research that involves more than one discipline (Frank, 1988). Around the same time, an increased interest in the meaning of integration at the postsecondary level surfaced, with emphasis on developing the "whole" person through the general education movement (Klein, 2005). Through the publication of a book called Integration: Its Meaning and Application (Hopkins, 1937), ideas of unity emerged but were quickly stifled, as participants in a meeting held by the National Education Association concluded that complete unity was impossible (Klein, 2005), clarifying that deeper knowledge in the disciplines was more important. This advocacy for disciplines dates back to Aristotle's influence in 387 BCE, when classical division of knowledge was enacted based on a hierarchy of disciplines, with philosophy at the top, physical and natural sciences following, and all other disciplines ranked by importance in a stepwise manner toward the bottom (Moran, 2002).

Although hints of interdisciplinarity slowly continued to be woven into research and education, little attention was paid to the underlying cultural and societal implications of interdisciplinarity until the 1960s. Philosopher Michel Foucault, guided by ideas from German philosopher Friedrich Nietzsche, stated that the separation of disciplines was not only a way to produce and categorize knowledge, but also a sophisticated means for "regulating human conduct and social relations" (Moran, 2002). Foucault believed that the hierarchical structure of disciplines legitimized and substantiated social and cultural power differentials by advantaging individuals who had the financial means to attend specialized, disciplinary training (e.g., college, trade school; Moran, 2002). This led to certain opportunities being funneled to a small subset of the population that had the disciplinary training and skill set required to occupy exclusive, high-paying professions (Katz, 2001).

During the Vietnam War and subsequent student revolutions, a shift in the nature of the academic environment began to take place (Repko, 2008). This shift edged toward Foucault's perspective, highlighting the limitations of disciplines' abilities to adequately address burgeoning social issues that characterized the period, such as the civil rights, anti-imperialism, and feminist movements (Katz, 2001). Thus, a desire for interdisciplinary connections between disciplines emerged. Nevertheless, this enthusiasm toward academic and social reform through interdisciplinary study wavered until pioneers in the humanities, namely, Julie Thompson Klein and William $\mathrm{H}$. Newell, resurrected its importance in the late 1970s (Repko, 2008). Klein began to question what constituted legitimate subjects of inquiry by examining the history, theory, and taxonomies surrounding interdisciplinarity (Klein, 1990, 1996, 2000). Newell formed a professional organization, the Association for Integrative Studies, and a journal, Issues in Integrative Studies, to analyze interdisciplinary methodology, curricula, and administration, both of which became a professional home for interdisciplinarians (Repko, 2008). Following their lead, incremental but consistent advances in interdisciplinary studies emerged in the social sciences and humanities (Weingart, 2010).

In the 21st century, this mode of thinking is increasingly being adopted in science, technology, engineering, and mathematics (STEM), as researchers struggle to answer radically complex issues from a single disciplinary viewpoint (Pellmar and Eisenberg, 2000; Welch, 2003; Masse et al., 2008; National Research Council [NRC], 2009; PCAST, 2012). An NRC report (2009) makes this clear in a "New Biology Initiative" aimed at achieving solutions to societal issues requiring "the creative drive and deep knowledge base of individual scientists from across biology and many other disciplines including physical, computational and geosciences, mathematics, and engineering" (p. 6). It further states, "Science and technology, alone, of course, cannot solve all of our food, energy, environmental, and health problems. Political, social, economic, and many other factors have major roles to play in both setting and meeting goals in these areas. Indeed, increased collaboration between life scientists and social scientists is another exciting interface that has much to contribute to developing and implementing practical solutions" (p. 10). The BIO2010 report (NRC, 2003) extends this need from interdisciplinary research to science education: "Exposing today's undergraduates to a more interdisciplinary curriculum will help them to better collaborate with their scientific peers in other disciplines as well as design more interdisciplinary projects on their own" (p. 2). In the wake of this ongoing revelation, Vision and Change catapulted interdisciplinarity to the forefront of life science higher education, by calling for students to tap into the interdisciplinary nature of science as one of six core competencies.

\section{INSTITUTIONAL BARRIERS}

In our intention to understand interdisciplinarity within an undergraduate environment, we would be remiss to ignore the university's role in reinforcing disciplinary boundaries in research and teaching practices. Establishing a productive research environment can be an important marker of a 
university's success and requires hiring experts trained in specific disciplinary areas. This brings in highly coveted skills and provides social recognition for successes and innovation at the department and institutional levels. Although disciplinary research undeniably produces essential building blocks of knowledge (Repko, 2008; Frodeman et al., 2017), attempts to cross over well-defined disciplinary boundaries can come with a battery of bureaucratic barriers, including research often being geared toward external funding and donor interests (Klein 1990, 1996; Giri, 2002). Until recently, funding agencies dominantly rewarded discipline-specific projects and proposals, thus placing higher value on disciplinary work, possibly at the expense of building knowledge across disciplines (Klein, 2000; Weingart, 2010). These reward structures favoring disciplinary work over interdisciplinary work inevitably impact academic culture and attitudes around interdisciplinary pursuits (Fennell and Sandefur, 1983; Klein, 1996; Gazzaniga, 1998; Weingart, 2010). Faculty may have diminished motivation to pursue interdisciplinary research if it is not recognized or rewarded.

A 1998 editorial in Science (Gazzinga, 1998) also discusses the modern university system being subdivided into disciplinary lines in science for the purpose of bureaucratic interests. Reward systems seem particularly salient in the sciences, given the heavy dependence on external funding. Further, if disciplinary research is incentivized in the university system, it inadvertently permeates teaching practices (Lattuca, 2001). For example, logistical issues associated with cross-listed courses from multiple departments can be complicated, with confusion about which department pays instructors, receives student tuition credit hours, and/or develops curricula that align with each department's vision. Furthermore, faculty hiring decisions are subject to the same departmental structures that preside over career advancements (e.g., promotion and tenure; Gazzaniga, 1998; Pellmar and Eisenberg, 2000). If departments mostly seek, hire, and promote faculty highly trained in discrete areas of science, a lack of expertise in interdisciplinary sciences will be a barrier to teaching interdisciplinary courses. Likewise, disciplinary identities among these faculty can trickle down to the students who are taught and mentored in such departments, potentially shaping students into scientists who embody similar identities (Pellmar and Eisenberg, 2000). Moran (2002) highlights the disciplinary reward system and teaching feedback loop:

\footnotetext{
The emergence of a new academic subject depends partly on internal factors: on elite universities recognizing [disciplines] through the creation of separate departments, sufficient students and lectures being recruited to study and teach it, learned societies and journals forming around it, and recognized career structures developing, usually based on the acquisition of a $\mathrm{PhD}$ in that subject. Moreover, since disciplines [are] influenced by such institutional factors, they tend, like many institutions, to reproduce themselves and become self-perpetuating (p. 13).
}

This is not to say that deep, grounded knowledge in disciplines is not advantageous. A traditional approach to disciplinary understanding serves great value and is necessary as "students begin to feel a sense of mastery and develop a professional identity" (Pellmar and Eisenberg, 2000, p. 59); however, expertise and identity may fall short of being able to address the rapid changes in the life sciences (NRC, 2003, 2009; PCAST, 2012). Being cognizant of such patterns is important as we seek to conceptualize and assess interdisciplinary understanding from the perspective of our students.

Despite various barriers that departments and practitioners may face, interdisciplinary science programs and courses are increasingly being developed and championed through funding agencies, with local and national incentivization for interdisciplinary collaborations among practitioners and students alike. As educators, we can begin to navigate the landscape by first identifying the core meaning of interdisciplinarity.

\section{A CONTENTIOUS DEFINITION}

A constellation of disciplinary hierarchy, departmental silos, and institutional barriers has created the perfect storm for a fractured understanding of the term "interdisciplinarity" (Bennington, 1999; Repko, 2008). This lack of common ground can be amplified in the sciences due to jargon, professional norms, and practices that vary across disciplines (Fennel and Sandefur, 1983). As there is a perception that interdisciplinary studies emerge from disciplines themselves (Fuchsman, 2009), it seems appropriate to first define its root word, "discipline": A "discipline" is a particular branch of learning or body of knowledge that can be distinguished by several factors, including the questions it asks via its ontological lens, epistemology, and methodology regarding how these ideas are used to contribute to a body of knowledge composed of concepts, theories, and facts (Newell and Green, 1982). Disciplinary knowledge can be a foundation by which we make sense of the world; however, each discipline comes with its own underlying assumptions and nuanced lens (Bauer, 1990; Repko, 2008). Exchanging those lenses for a unified eyepiece can require layered and intentional amalgamation of differing paradigms, which is by no means simple. As the borders between disciplines blur, epistemologies are challenged, which can in turn hinder integration (Guba and Lincoln, 1994; Rogers et al., 2005; Fuchsman, 2009).

Another discrepancy surrounding the definition of interdisciplinarity arises from its undefined role related to disciplinary foundations. Moran (2002) describes this discrepancy as "competing impulses"-in one camp, the concept of interdisciplinarity is founded on traditional disciplines through a "wide-ranging total knowledge of a single subject"; in the other camp, interdisciplinarity is radically subversive to this-it seeks to answer questions that cannot be answered by the very disciplinary foundations that support it. Furthermore, the etymology of the prefix "inter" can have multiple meanings: between or joining (e.g., intercellular or intercalate) to being separated and lying apart (e.g., interval or intervene; Bennington, 1999). Bennington states, "The term interdisciplinarity is slippery: It can suggest forging connections across the disciplines; but it can also mean establishing a kind of undisciplined space in the interstices between disciplines, or even attempting to transcend disciplinary boundaries altogether" (p. 104). Bennington suggests that this obscurity is what gave the term "interdisciplinarity" a myriad of synonyms with other prefixes-postdisciplinary, crossdisciplinary, pluridisciplinary, multidisciplinary, antidisciplinary, and transdisciplinary are often used interchangeably with the term "interdisciplinary," causing further ambiguity. This exchange of prefixes is directly reflected within the Vision and 
Change report, where the term "multidisciplinary" describes "interdisciplinary" practices in the fourth Core Competency, and calls for "cross-disciplinary" work to achieve connections between science and society in the last Core Competency (AAAS, 2011). For the purposes of this essay and to minimize confusion, we will use the term "interdisciplinarity"-the integration of multiple disciplines, leading to new ideas - to remain in line with the most common language and distilled meanings from national initiatives and literature. A more nuanced analysis of the definition is provided below.

Despite the aforementioned barriers, as researchers have taken detached pieces of information and/or tools from existing disciplinary frameworks-added, modified, deleted, or reshaped them to fill gaps of knowledge-new boundaries have been drawn, which we label as interdisciplinary fields (Repko, 2008). Sometimes, as mentioned previously, an "interdiscipline" becomes disciplinary in nature, such as sociobiology or biochemistry (Klein, 2000), creating a cyclical loop from disciplinary-to-interdisciplinary-to-new disciplinary fields. It takes time for a field to gain enough momentum to become a new discipline (Lattuca, 2001, Klein, 2005). Interdisciplinarity is a process-not an outcome-perhaps explaining slow recognition and adoption by disciplinary purists on the meaning and value of interdisciplinary studies.

\section{PROPOSED RESOLUTIONS}

\section{The Disciplines' Definitions}

Despite the historical, institutional, and etymological barriers surrounding interdisciplinary endeavors, literature in the social sciences and natural/physical sciences has attempted to define interdisciplinarity. "Interdisciplinary understanding" has been defined in social sciences as "the capacity to integrate knowledge and modes of thinking in two or more disciplines or established areas of expertise to produce a cognitive advancementsuch as explaining a phenomenon, solving a problem, or creating a product-in ways that would have been impossible or unlikely through single disciplinary means" (Boix Mansilla et al., 2000, p. 219).

The NSF has accepted the definition of "interdisciplinary research" set forth in a report from the National Academy of Sciences, National Academy of Engineering, and Institute of Medicine (NASEM, 2005): "Interdisciplinary research is a mode of research by teams or individuals that integrates information, data, techniques, tools, perspectives, concepts, and/or theories from two or more disciplines or bodies of specialized knowledge to advance fundamental understanding or to solve problems whose solutions are beyond the scope of a single discipline or area of research practice" (p. 2). The main difference between these two definitions resides in their objective-the former describes a way of understanding, while the latter involves the application of interdisciplinary research.

\section{The Faculty's Definition}

As the above definitions are derived from interdisciplinary understanding in the social sciences and interdisciplinary research in the natural and physical sciences, respectively, we sought for a definition targeted toward what interdisciplinary science might look like in the context of undergraduate science students. Current higher education faculty are on the frontline of planting the seeds for science students to start thinking inter-
TABLE 1. Top six emergent themes from surveyed science faculty $(n=184)$ on how they define interdisciplinary science ${ }^{a}$

\begin{tabular}{lrc}
\hline $\begin{array}{l}\text { Top themes among interdisciplinary science } \\
\text { definitions }\end{array}$ & $\boldsymbol{n}$ & $\%^{\mathbf{b}}$ \\
\hline $\begin{array}{l}\text { Involves two or more disciplines } \\
\text { Use of multiple/differing research methods/ }\end{array}$ & 79 & 94.0 \\
$\quad$ methodology & 43.0 \\
$\begin{array}{l}\text { Collaboration among individuals } \\
\text { Need for other/additional disciplinary knowledge/ }\end{array}$ & 52 & 28.3 \\
$\quad$ expertise & 52 & 28.3 \\
$\begin{array}{l}\text { Having various perspectives, theories, approaches } \\
\text { Addresses problems that cannot be solved by one }\end{array}$ & 48 & 26.1 \\
$\quad$ discipline & 37 & 20.1
\end{tabular}

anterrater reliability of greater than $80 \%$ was obtained.

'Themes do not add up to $100 \%$, as individuals made statements that were coded to multiple themes.

disciplinarily. Yet there is little understanding of how faculty conceptualize interdisciplinary science from either the research perspective or the pedagogical perspective. To establish a universal definition addressing both of these aspects, we collected multiple definitions of "interdisciplinary science" by surveying faculty across scientific disciplines and departments, asking, "How do you define interdisciplinary science?" (see the Supplemental Material for sample demographics). Three researchers (including B.T.) conducted content analysis of 184 open-ended survey responses resulting in six salient themes (Table 1 ). Interrater reliability of $>80 \%$ was obtained through multiple iterations of prevalent themes on 80 responses, resulting in a final codebook. All three researchers then equally divided the remaining 104 responses and coded them based on thematic identification. As a final check for coding consistency, an additional researcher unrelated to the initial coding process, but trained on the project details and application of the codebook, examined all survey responses for accuracy of themes. We used the emergent themes and our analysis of the literature to develop a working definition of interdisciplinary science, with the intention of it being relevant to undergraduate science students and experts alike.

Five of the six salient themes from faculty responses offered definitions of interdisciplinary science that contain constituent parts from both of the previously presented definitions from the social sciences literature and scientific research funding agencies. A theme that was regularly included in our participants' and NSF's definition, but was excluded from the social science literature, was the idea that interdisciplinarity involves "collaboration" (Table 1). The relevance of this theme is supported by a study that explored learning outcomes for graduate students involved in the NSF's (former) Integrative Graduate Education and Research Traineeship (IGERT) program (Borrego and Newswander, 2010). Using elements from the humanities (Repko, 2008) and an interdisciplinary social science rubric (Boix Mansilla et al., 2009), researchers compared IGERT grant proposals with the rubric to look for interdisciplinary elements in the pursuit of developing interdisciplinary graduate student learning outcomes. Their findings provided a compelling argument that collaboration is an essential factor for interdisciplinary work in the natural and physical sciences. This should come as no surprise, as science is simply too vast 
for any one individual to be an expert in the multiple fields necessary to solve complex issues (NRC, 2003, 2009). Thus, we propose a working definition of interdisciplinary science derived from a survey of science faculty and various published work:

Interdisciplinary science is the collaborative process of integrating knowledge/expertise from trained individuals of two or more disciplines-leveraging various perspectives, approaches, and research methods/methodologies - to provide advancement beyond the scope of one discipline's ability.

Aside from collaboration being identified as essential to interdisciplinary science, all three definitions are not markedly different from one another. This suggests that science faculty are indeed aware of the key elements involved in interdisciplinary science as defined by STEM and non-STEM disciplines; however, whether they are also developing learning goals related to this competency remains unknown. Of 184 faculty participants in our survey study, 45\% $(n=84)$ did state having interdisciplinary learning outcomes in response to the question "Does your course have learning outcomes related to students' understanding of the interdisciplinary nature of science?" With ongoing calls for interdisciplinary science efforts, it is important to determine how we can better support faculty to create and embed learning outcomes related to interdisciplinary science for undergraduates. Here, we aim to provide an evidence-based launch point for undergraduate instructors to develop learning goals and outcomes related to interdisciplinary science practices. This study was approved by Portland State University's Internal Review Board \#174219.

\section{CONCEPTUAL FRAMEWORK}

We leveraged the science faculty definition as a blueprint for developing a framework for educators to engage undergraduate students in interdisciplinary understanding. The theoretical base of our model incorporated constructs from researchers who suggest that students need multiple ways of knowing to address interdisciplinary understanding, including: a basic understanding of contributing disciplines (disciplinary grounding) and how the disciplines integrate to advance the solution of a question toward a common goal (advancement through integration; Boix Mansilla and Duraisingh, 2007; Öberg 2009). The influence of these two interrelated criteria, combined with the concept of "disciplinary humility," gleaned from the environmental sustainability literature (Byrne et al., 2016), and "different research methods" and "collaboration across disciplines," salient constructs from our faculty experts, formed the groundwork for our conceptual model: the IDSF (Figure 1). In the next part of this essay, we provide justification for the selection and inclusion of these five criteria we have found to be relevant to interdisciplinarity in the natural and physical sciences. By defining these elements, we intend for practitioners to conceptualize and identify activities and anticipated learning outcomes that foster and demonstrate students' interdisciplinary science understanding. On a much broader scale, we hope that this framework serves as a platform to foster communication and collaboration within and between STEM and non-STEM disciplines.

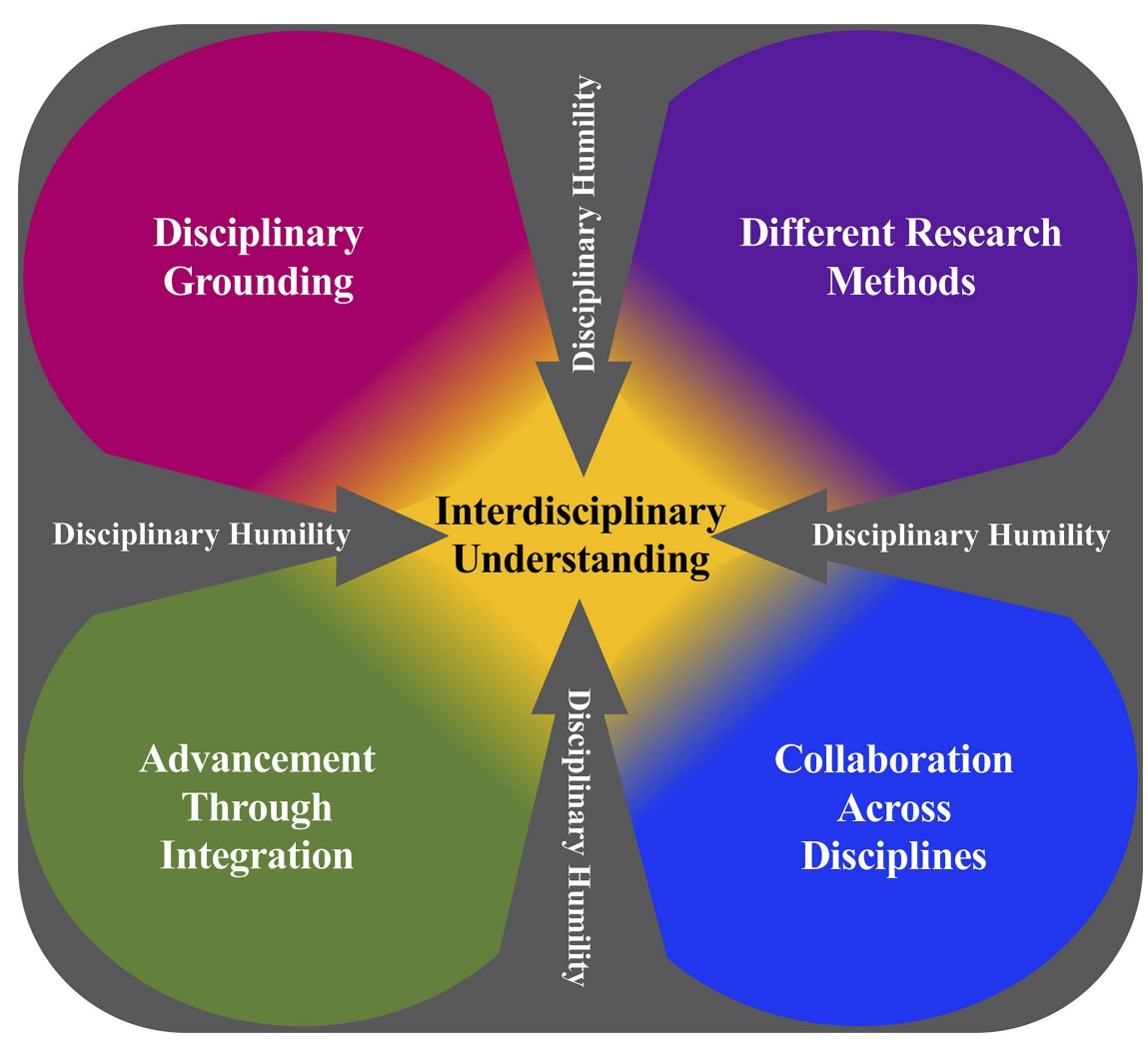

FIGURE 1. Interdisciplinary Science Framework (IDSF) for guiding students to tap into the interdisciplinary nature of science.

\section{Criteria Outlined}

Disciplinary Humility. As students begin an exploration of disciplines outside their majors, developing a mindset, or epistemic perspective, that is infused with humility, inclusivity, and respect for other disciplinary epistemologies is a foundational criteria we label "disciplinary humility." Disciplinary humility has been deemed a "prerequisite to and basis for transdisciplinary conversations and transcendent knowledge generation" (Byrne et al., 2016 , p. 14). We have adapted and applied this phrase to interdisciplinary understanding-in order to work across disciplines, it is imperative to remain reflexive about one's limitations in knowledge, skill, and awareness of personal biases (NRC, 2015). We encourage students to start this metacognitive effort by infusing disciplinary humility into their mindsets at the inception of interdisciplinary thinking, research, and collaborations. Doing so will allow space for respectful evaluation of similarities and differences between disciplines and among individuals.

We suggest that undergraduate STEM students can acquire disciplinary humility by making connections between STEM and non-STEM disciplines in relation to 
real-world issues. Students should be given the opportunity to recognize how STEM disciplines constantly interface with society, policy, economy, community relations, and relevant stakeholders to effectively progress toward workable solutions (NRC, 2003, 2009; AAAS, 2011; Bammer, 2013). Longitudinal comparisons of STEM students engaged in interdisciplinary work that intersects with the social sciences and humanities have shown that these populations have more receptivity to new ideas, are more sensitive to ethical issues due to the exposure of non-STEM perspectives, integrate disciplinary insights more holistically, exhibit more humility, and "move beyond tolerance to a celebration of diversity" (Newell, 1990, p. 70). Likewise, we believe that the acquisition and growth of disciplinary humility has the potential to reduce the positive-feedback loop of disciplinary superiority and is therefore a thread that runs throughout the IDSF.

Disciplinary Grounding and Different Research Methods. As students begin their journeys toward interdisciplinary science understanding, a grounding in disciplinary knowledge must be present. The notion that a student should develop a strong disciplinary grounding has been recommended to reduce the risk of "a mile wide and an inch deep" or a "light educational experience" (Boix Mansilla and Duraisingh, 2007). We agree that, if no foundation of disciplinary knowledge is present, the ability to draw accurate connections between disciplines would be tenuous. Clearly, the depth of a student's knowledge (on a novice to expert scale) in any one discipline will depend on programmatic expectations and vary among individuals' past experiences and knowledge. Although many students do begin to develop robust disciplinary-knowledge platforms, requiring undergraduate students to be experts in any one discipline, let alone all disciplines involved, is likely unreasonable (Boix Mansilla and Duraisingh, 2007; Full et al., 2015). We suggest that being grounded in disciplinary content means that students must be at least provisionally knowledgeable in possible disciplines involved in a question or activity at hand, yet maintain accessible, deeper knowledge from a single discipline. For example, if a student/student group is tasked with solving a problem regarding declining bee populations, a plant biology major will have discipline-specific knowledge to contribute, such as factors influencing plant-pollinator interactions; yet that student may have less depth of (but provisional) knowledge regarding agriculture, chemistry, and climatological factors influencing honeybee populations. The NRC (2009) supports this idea: "The New Biologist is not a scientist who knows a little bit about all disciplines, but a scientist with deep knowledge in one discipline and a 'working fluency' in several" (p. 89).

Alongside the development of disciplinary knowledge, acquisition of different research methods can aid in students' operationalization of how best to tackle real-world problems. In our search for an all-encompassing definition from faculty, the inclusion of different research methods was indeed a seminal theme in interdisciplinary science (Table 1). Reinforcing this idea, the Committee on Facilitating Interdisciplinary Research (NASEM, 2005) suggested that "educators should facilitate interdisciplinarity by providing educational and training opportunities for undergraduates... such as data gathering and analysis, and research activities [connected] to other fields of study and to society at large" (p. 5).
We would like to distinguish research methods from methodology: methods are the tools and/or instruments used to answer a problem or research question, while methodology is the deep, philosophical assumptions and rationale for using said methods (Hyett et al., 2014). Undergraduates may not have enough exposure to philosophical or epistemological rationales for why certain methods are used, especially across non-STEM disciplines. Current undergraduate science curricula are often lacking ontological and epistemological underpinnings that govern disciplinary bodies of knowledge, contributing to students falling short in these areas (Lederman, 2007; Vázquez Alonso et al., 2016). But it is reasonable for students to understand the general purpose of using different methods such that they can create a tool kit of possible techniques/instruments that are appropriate from each discipline. To reach beyond a "grab bag" of methods, we encourage integration and collaboration between individuals who hold disciplinary expertise, potentially incorporating more methodological reasoning behind the selected methods.

Integration and Collaboration. Another criterion outlined by Boix Mansilla and Duraisingh (2007) was "advancement through integration," which included the "capacity to use knowledge flexibly." Students should be able to use previous information flexibly to create new understanding or knowledge, rather than regurgitating siloed pieces of information that were given to them. When students use knowledge flexibly, they can apply different pieces of disciplinary knowledge in a unique way that culminates in an outcome that would not have been possible through the use of one discipline alone. This means that students are not only collecting the appropriate disciplinary pieces of information and placing them in a central repository, but are also proficient at integrating-mixing, connecting, and applying them to discover new insights or ideas. A defining element of integration is combining disciplinary components into unique combinations to produce a product entirely distinguishable from its constituent parts. In doing so, the whole becomes greater than the sum of the individual disciplines (Newell, 1990; Boix Mansilla and Duraisingh, 2007). Students can best accomplish this by collaboratively leveraging different disciplinary chunks of knowledge, methods, and methodological reasoning to advance their understanding.

The fourth criterion, collaboration, is an interaction that complements and enhances all previous criteria and would likely help students develop disciplinary humility, understand their own disciplinary grounding, expand their awareness of the purpose of various research methods/methodologies, and achieve integration across disciplines. Although collaboration is best embodied through the practice of interdisciplinarity and the participation of players, students may not have opportunities to engage in interdisciplinary research and collaboration during their undergraduate careers, as indicated by an overwhelming call for interdisciplinary ideas in undergraduate education. However, we uphold that students can at least start thinking and preparing for interdisciplinary collaborations by identifying markers that make collaboration successful. A successful collaboration involves the establishment of common ground (Lattuca, 2001; Klein, 2005; Öberg, 2009). According to a National Academy of Sciences study (NASEM, 2005) on interdisciplinary research, "Researchers desiring to work on 
interdisciplinary research, education, and training projects should immerse themselves in the languages, cultures, and knowledge of their collaborators" (p. 4). Scholars suggest that "newcomers" to interdisciplinarity, however, do not spend enough time on creating common ground, which leads to frustration, anger, inability to cope, and ultimately discontinued work. Ways to circumvent these barriers involve becoming aware of one's own tradition (disciplinary grounding) and becoming familiar with traditions of other disciplines (content, perspectives, and associated research methods). Another aspect of common ground involves identification of commonalities and discrepancies (Klein, 2005): What are the terms/phrases and underlying assumptions between disciplines? Do they have similarities (meaning of electrical current in physics vs. electrical current in biology)? Do they have differences (meaning of heat in climatology vs. thermal energy in chemistry)? To identify these similarities and differences, each member of the collaboration must approach the partnership with an open mind (disciplinary humility) and an aim of integrating each contributing discipline to further advance the solution beyond the capability of a single discipline (advancement through integration).

Öberg (2009) suggests that the final part of establishing common ground is sharpening the aim of the research question or issue-this involves anchoring the approach all the way from the framing of the study or solution, to the choice and use of methods and into the analysis. In the evolution of becoming a team, individuals from both STEM and non-STEM disciplines can leverage one another to frame the study appropriately through disciplinary grounding, selection of different research methods appropriate to the research question or problem, familiarity with the general purpose behind certain methods and a deeper understanding of other disciplines' methodologies, and analysis of how each discipline will be integrated to contribute to the whole. Through the ongoing infusion of disciplinary humility, these pieces can coalesce in an integrated manner.

\section{Applying the IDSF to Curricula}

To set the stage for students to understand the interdisciplinary nature of science, faculty will need to create authentic opportunities for students to think about and/or engage in interdisciplinary science. Here, we provide several examples of studies that highlight elements of the IDSF in their published instructional materials (Table 2).

When designing interdisciplinary curricula, instructors may grapple with the degree of appropriate integration between disciplines. Newell (1990) reviews several mechanisms to support varying levels of integration-from traditional disciplinary courses that borrow one learning objective from another discipline, to fully integrated courses that have no disciplinary divisions. Gouvea et al. (2013) provide a useful guide for instructors to assess what level of interdisciplinarity must be present to support the learning objectives of science instruction when designing interdisciplinary curricular tasks.

Many researchers recognize that students must be provided with baseline knowledge from contributing disciplinary perspectives, methods, and ways of addressing questions about the real world before they can successfully integrate those disciplinary pieces of information (Newell, 1990; Boix Mansilla and
Duraisingh, 2007; Repko, 2008; Gentile et al., 2012). Watkins et al. (2012) highlight the importance of disciplinary grounding as they expose students to what they deem "disciplinary authenticity." The authors contextualize how methods used by physicists and biologists can address similar phenomena in different but complementary ways. For example, they describe how physicists may employ concepts of van der Waals forces and capillarity action when investigating how geckos climb smooth surfaces, while evolutionary biologists may examine the anatomy of modern-day gecko toes and compare them with fossils of geckos' prehistoric ancestors. Here, students were able to examine different disciplinary methods and concepts to better understand multiple angles of the same phenomenon. In a more heavily emphasized disciplinary approach, Gouvea et al. (2013) and Thompson et al. (2013) introduced interdisciplinary science concepts only after students had exposure to prerequisite disciplinary courses, as this provided students with firm disciplinary knowledge that could then be integrated and applied toward interdisciplinary problems.

The implementation of modules has been a popular approach to integrating physics and biology courses, as adoption of such practices are easier to embed into a course than redesigning an entire curriculum. Thompson et al. (2013) reports on the National Experiment in Undergraduate Science Education project, which integrates modules containing basic understanding of biological and physical properties and general scientific skills, such as modeling, problem solving, multiple scientific representations, and experimental design. Similarly, Woodin et al. (2013) provide an extensive list of 11 projects that feature modules and materials for specific courses that advance integration though different disciplinary research methods and concepts, including active-learning activities that involve collaboration across disciplines. The BIO2010 report (NRC, 2009) provides a comprehensive review of modules that support integration of STEM disciplines, as well as useful websites that compile interdisciplinary science education resources. Examples of project-based laboratories that compile different research methods from STEM disciplines are also covered, further elucidating the importance of interdisciplinary laboratory skills. In addition, a study by Full et al. (2015) outlines a framework for interdisciplinary laboratory courses that involved students rotating between "stations" of different disciplines where they learned concepts and research techniques. This was followed by students collaboratively addressing a novel issue by employing the different methods that they learned from each discipline.

Another common thread in the literature is an increase in the number of different disciplinary faculty required to develop interdisciplinary curricula. In particular, collaboration between faculty in different disciplines was necessary to correctly identify commonalities and overlapping concepts among disciplines (NRC, 2009). For instance, Redish and Cooke (2013) provide a case study of two faculty members' efforts in developing curricula bridging physics and biology by acknowledging commonalities and differences, and as a by-product, an increased space for common ground and mutual respect of each other's disciplinary domains were developed (i.e., disciplinary humility). This could be an opportunity to transfer these lessons to students: allowing students to work in tandem with one another, ideally students from different majors, could potentially foster disciplinary humility through collaboration. 
TABLE 2. Review of interdisciplinary instructional studies that align with the IDSF criteria

\begin{tabular}{|c|c|c|c|c|c|c|}
\hline References & Resources & $\begin{array}{c}\text { Disciplinary } \\
\text { grounding }\end{array}$ & $\begin{array}{l}\text { Different } \\
\text { research } \\
\text { methods }\end{array}$ & Integration & Collaboration & $\begin{array}{c}\text { Disciplinary } \\
\text { humility }\end{array}$ \\
\hline Full et al., 2015 & $\begin{array}{l}\text { Framework for creating } \\
\text { interdisciplinary labs }\end{array}$ & $\checkmark$ & $\checkmark$ & $\checkmark$ & $\checkmark$ & \\
\hline NRC, 2009 & $\begin{array}{l}\text { Examples of modules, teaching } \\
\text { materials, interdisciplinary } \\
\text { content and laboratory } \\
\text { guidelines }\end{array}$ & $\checkmark$ & $\checkmark$ & $\checkmark$ & $\checkmark$ & \\
\hline Woodin et al., 2013 & $\begin{array}{l}\text { Provides } 11 \text { projects that feature } \\
\text { materials to embed in specific } \\
\text { courses or modules }\end{array}$ & $\checkmark$ & $\checkmark$ & $\checkmark$ & $\checkmark$ & \\
\hline Gouvea et al., 2013 & $\begin{array}{l}\text { Framework for analyzing models, } \\
\text { graphs, and essay questions }\end{array}$ & $\checkmark$ & $\checkmark$ & $\checkmark$ & & $\checkmark$ \\
\hline Gentile et al., 2012 & $\begin{array}{l}\text { Examples and materials for } \\
\text { integrating STEM disciplines }\end{array}$ & $\checkmark$ & $\checkmark$ & $\checkmark$ & & \\
\hline Thompson et al., 2013 & $\begin{array}{l}\text { Examples of modules that integrate } \\
\text { physics and biology }\end{array}$ & $\checkmark$ & $\checkmark$ & $\checkmark$ & & \\
\hline Newell, 1990 & $\begin{array}{l}\text { Instructor guidelines for implement- } \\
\text { ing interdisciplinary curricula }\end{array}$ & $\checkmark$ & & $\checkmark$ & $\checkmark$ & $\checkmark$ \\
\hline Weber, 2016 & $\begin{array}{l}\text { Examples of multiscalar topics that } \\
\text { address real-world problems }\end{array}$ & $\checkmark$ & & $\checkmark$ & $\checkmark$ & $\checkmark$ \\
\hline Watkins et al., 2012 & $\begin{array}{l}\text { Examples of how to create exams } \\
\text { and homework questions that } \\
\text { use concepts and tools from } \\
\text { biology and physics to address a } \\
\text { similar problem }\end{array}$ & $\checkmark$ & $\sqrt{ }$ & & & \\
\hline Redish and Cooke, 2013 & $\begin{array}{l}\text { Case study on instructor perspectives } \\
\text { of disciplinary humility and } \\
\text { collaboration }\end{array}$ & $\checkmark$ & & & & $\checkmark$ \\
\hline Eigenbrode et al., 2007 & $\begin{array}{l}\text { Provides a toolbox for facilitating } \\
\text { different philosophical } \\
\text { perspectives and aspects of } \\
\text { research }\end{array}$ & & & & $\checkmark$ & $\checkmark$ \\
\hline
\end{tabular}

In our curricular review, we noted a paucity of literature on partnerships and connections outside STEM disciplines, possibly for reasons related to the sociohistorical and institutional challenges of interdisciplinarity previously discussed in this essay. Similarly, there are reports of a pervasive attitude among STEM students about what science is and is not, deeply rooted in epistemic beliefs about what constitutes domains of scientific knowledge (Redish and Hammer, 2009; Gouvea et al., 2013). This often comes at the expense of non-STEM disciplines. We propose that changing these attitudes starts with faculty providing real-world applications for students to connect science and society.

Although the need for students to connect social sciences and humanities to STEM is not explicitly stated in Vision and Change (AAAS, 2011), it is impossible to address the complex issues of today without connecting STEM and non-STEM disciplines. Science instructors ought to inclusively teach science as it exists in the real-world-in constant flux between and within cultural, social, and political influences (NRC, 2009). Situating interdisciplinary science pedagogy in the context of students' everyday lives (real world) can thus provide relevance and pathways to meaningful learning (Newell, 1990; Weber, 2016; Cooper and Stowe, 2018). In this vein, Newell (1990) recommends a topical approach to interdisciplinary pedagogy in which instructors design curricula through the lens of a relatively broad but singular, complex topic such as "energy crisis," pulling on the perspectives of chemistry, physics, geology, biology, mental health, and community. These topical approaches not only provide an avenue for students to naturally integrate seemingly disparate disciplines, but can develop a level of disciplinary humility by recognizing the necessity of non-STEM disciplines. Similarly, to facilitate disciplinary humility more directly, opportunities for philosophical dialogue regarding other disciplines should also be woven into curricula. Eigenbrode et al. (2007) provide a toolbox of questions designed to marry competing philosophical aspects of disciplinary research and may aid in STEM students' inclusion of non-STEM disciplines and their development of disciplinary humility.

\section{IDSF Curricular Example}

To provide a concrete example of how to apply our theoretical model to a classroom, this section outlines a module developed with the IDSF through backward design. Backward design is a pedagogical strategy that intentionally aligns learning goals, outcomes, assessments, and activities (Wiggins and McTighe, 1998; Handelsman et al., 2007). We present a hypothetical upper-division environmental science course that uses a novel, active-learning pedagogy called deliberative democracy 
(DD) designed by researchers at Portland State University (Komperda et al., 2018). The goal of DD is to introduce modern issues in science and society, and have students work in peer groups to reach consensus on how to address a complex, realworld problem that relates to scientific topics learned in the course. Here, we use DD to challenge students to address the problem of declining honeybee populations. We then assess students' knowledge through a group worksheet followed by an individual writing assignment.

First, we recommend selecting learning goals based on the five criteria in the IDSF (Table 3). Students could be assigned to groups of six and tasked with identifying what disciplines may need to be involved to fully address the problem of declining honeybee populations. Next, students could assign disciplinary roles to one another, representative of the disciplines needed to tackle the problem, such as: an agronomist, an entomologist, an evolutionary biologist, an organic chemist, a climatologist, and an anthropologist. Students then independently research the discipline they are assigned as it relates to the issue. Students reconvene to collaboratively discuss relevant disciplinary knowledge and what research methods to use and why, as well as the limitations of their disciplinary role. For example, an entomologist would provide knowledge on honeybees and their social systems, but would require the knowledge of an agronomist, evolutionary biologist, chemist, climatologist, and an anthropologist to fully understand the implications of factors such as changes in farming, genetic disruptions, and environmental shifts that all relate to the honeybee decline, as well as the social impacts (cultural implications and health-related issues in areas that rely heavily on food produced by honeybee pollinations). Deep discussion and deliberation involving the what, how, and why behind each disciplinary contribution is necessary in this phase. Through a growing mutual respect (disciplinary humility), students could then collectively decide how each discipline and method(s) will be leveraged to remediate the issues involved in declining honeybees, culminating in a new discovery or insight about this societal issue (integration).

For an instructor to identify whether learning goals are being met, formative and summative assessments can be embedded into the curriculum (Handelsman et al., 2007; Table 3). As a group, students could discuss, complete, and submit a worksheet containing questions related to the honeybee issue (for example worksheets, see "Deliberative Democracy"; Portland State University, 2019). Instructors could develop quiz and/or exam questions related to the activity to assess whether students are making connections across disciplines and understanding related content. This could be followed by an individual writing-intensive assignment (e.g., essay, proposal, research paper) with students scored on the basis of their inclusion of criteria from the IDSF. These assessment examples could provide evidence that students are meeting associated learning goals while giving students opportunities to apply their interdisciplinary science knowledge to new situations. Table 3 can be modified to include various interdisciplinary science topics or problems and collaborative and/or individual activities of the instructor's choice.

\section{IMPLICATIONS FOR CORE COMPETENCIES}

In addition to students being able to tap into the interdisciplinary nature of science (Competency 4), Vision and Change suggests five other Core Competencies that undergraduate biology students must cultivate by the end of their degree programs. Core Competencies 1, 2, and 3 are action skills that task students to 1) apply the process of science, 2) use quantitative reasoning, and 3) use modeling and simulation; and the last two Core Competencies, 5 and 6, are the ability: 5) to communicate and collaborate with other disciplines and 6) to understand the relationship between science and society. We hypothesize that, as students cycle through the criteria outlined in the IDSF, they are also likely to at least be thinking about the other competencies. We have made the case that once students can apply and use common scientific practices with disciplinary grounding, different research methods, and humility (Competencies 1-3), they may be well prepared to work effectively with others to solve interdisciplinary problems. As illustrated in our definition of interdisciplinary science and recommendations for designing curricula, communicating and collaborating with other disciplines (Competency 5) is an integral part of working interdisciplinarily, and is thus inextricably linked to the ability to tap into the interdisciplinary nature of science (Competency 4). And finally, Core Competency 6, understanding the relationship between science and society, is at the root of many interdisciplinary efforts. If scientific mandates require students to be better prepared to address the complex issues of society, providing them an opportunity to address real-world problems may foster science and society connections.

We would like to emphasize that only as students near the end of their undergraduate degrees would they become proficient in understanding the complete nature of interdisciplinary science. Therefore, we foresee that undergraduates will not fully harness all constructs of the IDSF just after completing their introductory courses, but additively over time. If students meet the criteria outlined in the IDSF, they will ideally be prepared to apply those skills to work interdisciplinarily. And if students are granted an authentic opportunity to work in interdisciplinary groups to solve real-world problems, then undergraduates will conceivably be meeting all six of the core competencies outlined in Vision in Change.

\section{A CALL FOR ADVANCEMENT}

In the face of challenges encountered in interdisciplinary science, the contributions of the IDSF coupled with curricular suggestions is a small, yet important, step forward in addressing the interdisciplinary science demands of this century. We realize that the deep sociohistorical challenges that may undermine interdisciplinary integration are difficult to navigate and warrant further review and additional research. As a starting point, we aim for the criteria in our model to provide helpful targets for researchers to begin to answer the more difficult questions that the IDSF poses: What levels of integration are necessary to develop true interdisciplinary understanding? How much integration must be enforced to solve real-world problems? How much breadth of disciplinary knowledge can be afforded before depth becomes sacrificed? What does disciplinary humility look like in the classroom?

The largest, and perhaps most challenging, question from this essay lands on the doorstep of academic culture-What changes must be made within academic culture to move beyond interdisciplinary importance to actually providing interdisciplinary opportunities to students? More attention to and 


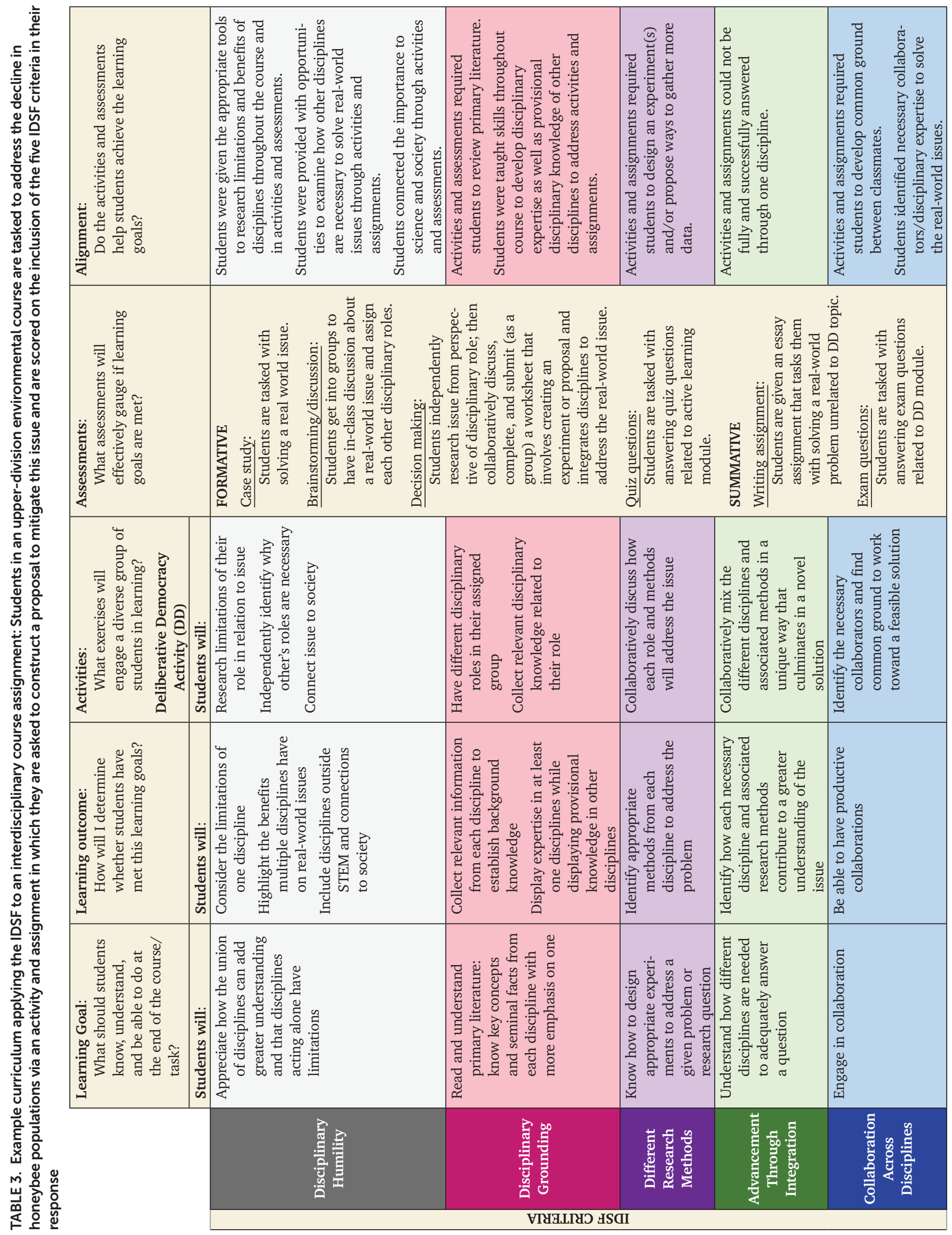


advancements in interdisciplinary science education must occur for us to answer these small- and larger-scale questions. Our hope is that researchers and educators can use the IDSF to begin to address these issues.

\section{CONCLUSION}

The ability for undergraduate biology students to "tap into the interdisciplinary nature of science" is relevant and important, yet challenging to understand and operationalize. Here, our intention was to clarify what this competency might reasonably look like as an expected outcome for biology undergraduates. We discuss interdisciplinary studies through its history, barriers, and multiple definitions, ultimately constructing a working definition of interdisciplinary science that can be applied to undergraduate education. We provide a platform, the IDSF, supported by current interdisciplinary curricula, and an example from which educators can begin scaffolding elements of interdisciplinary understanding into their classrooms. Practitioners are encouraged to begin formulating curricula through backward design to meet criteria described in the IDSF, which we hope will be broadly useful for undergraduate students in all STEM fields as they move through their studies and into the workforce. By embedding the elements of interdisciplinary thinking and understanding into our undergraduate science curricula, we will begin to prepare students to effectively untangle the complicated challenges of today, ultimately tapping into the interdisciplinary nature of science. More broadly, and perhaps ambitiously, we ultimately envision the IDSF as a foundation for promoting institutional change surrounding the deeper sociohistorical issues embedded in academic culture.

\section{ACKNOWLEDGMENTS}

We thank the faculty participants who generously offered their perceptions on interdisciplinary science. We thank Alexa Clemmons, Alison Crowe, Sophia Voronoff, and Analee Pham for their reviews of previous drafts of the article and Vivek Shandas for engaging us in insightful interdisciplinary conversations. We also thank the Biology Education Research Group at PSU for feedback on article revisions.

\section{REFERENCES}

American Association for the Advancement of Science. (2011). Vision and change: A call to action, final report. Washington, DC. Retrieved July 3 , 2018, from http://visionandchange.org/finalreport

Bammer, G. (2013). Disciplining interdisciplinarity: Integration and implementation sciences for researching complex real-world problems. Canberra, Australia: ANU Press.

Bauer, H. H. (1990). Barriers against interdisciplinarity: Implications for studies of science, technology, and society (STS). Science, Technology, \& Human Values, 15(1), 105-119.

Bennington, G. (1999). Inter. In McQuillan, M., MacDonald, G., Purves, R., \& Thompson, S. (Eds.), Post-theory: New directions in criticism (pp. 103119). Edinburgh: Edinburgh University Press.

Boix Mansilla, V., \& Duraisingh, E. D. (2007). Targeted assessment of students interdisciplinary work: An empirically grounded framework proposed. Journal of Higher Education, 78(2), 215-237.

Boix Mansilla, V., Duraisingh, E. D., Wolfe, C. R., \& Haynes, C. (2009). Targeted assessment rubric: An empirically grounded rubric for interdisciplinary writing. Journal of Higher Education, 80(3), 334-353.

Boix Mansilla, V., Miller, W. C., \& Gardner, H. (2000). On disciplinary lenses and inter-disciplinary work. In Wineburg, S., \& Grossman, P. (Eds.), Interdisciplinary curriculum: Challenges to implementation (pp. 17-38). New York: Teachers College Press.
Borrego, M., \& Newswander, L. K. (2010). Definitions of interdisciplinary research: Toward graduate-level interdisciplinary learning outcomes. Review of Higher Education, 34(1), 61-84.

Byrne, E., Sage, C., \& Mullally, G. (2016). Transdisciplinarity perspectives on transitions to sustainability. Routledge.

Cooper, M. M., \& Stowe, R. L. (2018). Chemistry education research-From personal empiricism to evidence, theory, and informed practice. Chemical Reviews, 111, 6053-6087

Eigenbrode, S. D., O'Rourke, M., Wulfhorst, J. D., Althoff, D. M., Goldberg C. S., Merrill, K., ... \& Bosque-Pérez, N. A. (2007). Employing philosophical dialogue in collaborative science. BioScience, 57(1), 55

Fennell, M. L., \& Sandefur, G. D. (1983). Structural clarity of interdisciplinary teams: A research note. Journal of Applied Behavioral Science, 19(2), $193-202$.

Frank, R. (1988). "Interdisciplinary": The first half century. Issues in Integrative Studies, 40(6), 139-151.

Frodeman, R., Klein, J. T., \& Pacheco, R. C. D. S. (Eds.). (2017). The Oxford handbook of interdisciplinarity. Oxford, UK: Oxford University Press.

Fuchsman, K. (2009). Rethinking integration in interdisciplinary studies Issues in Integrative Studies, 85(27), 70-85.

Full, R. J., Dudley, R., Koehl, M. A. R., Libby, T., \& Schwab, C. (2015). Interdisciplinary laboratory course facilitating knowledge integration, mutualistic teaming, and original discovery. Integrative and Comparative Biology, 55(5), 1-14.

Gazzaniga, M. S. (1998). How to change the university. Science, 282(5387), 237.

Gentile, L., Caudill, L., Fetea, M., Hill, A. L., Hoke, K., Gentiles, L., ... \& Szajda, D. (2012). Challenging disciplinary boundaries in the first year: A new introductory integrated science course for STEM majors. Journal of College Science Teaching, 41(5), 44-50.

Giri, A. K. (2002). The calling of a creative transdisciplinarity. Futures, 34(1) $103-116$

Gouvea, J. S., Sawtelle, V., Geller, B. D., \& Turpen, C. (2013). A framework for analyzing interdisciplinary tasks: Implications for student learning and curricular design. CBE-Life Sciences Education, 12(2), 187-205.

Guba, E. G., \& Lincoln, Y. S. (1994). Competing paradigms in qualitative research. In Denzin, N. K., \& Lincoln, Y. S. (Eds.), Handbook of qualitative research (pp. 105-117). Thousand Oaks, CA: Sage Publications.

Handelsman, J., Ebert-May, D., Beichner, R., Bruns, P., Chang, A., DeHaan, R., .. \& Wood, W. B. (2007). Scientific teaching. New York: Freeman.

Hopkins, L. T. (1937). Integration: Its meaning and application. New York: Appleton-Century.

Hyett, N., Kenny, A., \& Dickson-Swift, V. (2014). Methodology or method? A critical review of qualitative case study reports. International Journal of Qualitative Studies on Health and Well-Being, 9(1), 23606.

Katz, C. (2001). Response: Disciplining interdisciplinarity. Feminist Studies, 27(2), 519-525.

Klein, J. T. (1990). Interdisciplinarity: History, theory, and practice. Detroit, MI: Wayne State University Press.

Klein, J. T. (1996). Crossing boundaries: Knowledge, disciplinarities, and interdisciplinarities. Charlottesville: University of Virginia Press.

Klein, J. T. (2000). A conceptual vocabulary of interdisciplinary science. In Stehr, N., \& Weingart, P. (Eds.), Practising interdisciplinarity (pp. 3-24). Toronto, Canada: University of Toronto Press.

Klein, J. T. (2005). Integrative learning and interdisciplinary studies. Peer Review, 7(4), 8-10.

Klein, J. T. (2015). Reprint of "Discourses of transdisciplinarity: Looking back to the future." Futures, 65, 10-16.

Komperda, R., Barbera, J., Shortlidge, E. E., \& Shusterman, G. P. (2018) Connecting chemistry to community with deliberative democracy. In Maguire, C. F., \& Sheardy, R.D. (Eds.), Citizens first! Democracy, social responsibility, and chemistry: ACS Symposium Series, 1297, 81-98.

Lattuca, L. R. (2001). Creating interdisciplinarity: Interdisciplinary research and teaching among college and university faculty. Nashville, TN: Vanderbilt University Press.

Lattuca, L. R., \& Knight, D. B. (2010). In the eye of the beholder: Defining and studying interdisciplinarity in engineering education. In Proceedings of 
the 117th annual conference of the American Society of Engineering Education. Louisville, KY: American Society for Engineering Education.

Lederman, N. G. (2007). Nature of Science: Past, present, and future. In Abell, S. K., \& Lederman, N. G. (Eds.), Handbook of research on science education (pp. 831-879). Mahwah, NJ: Lawrence Erlbaum Publishers.

Masse, L. C., Moser, R. P., Stokols, D., Taylor, B. K., Marcus, S. E., Morgan, G D., ... \& Trochim, W. M. (2008). Measuring collaboration and transdisciplinary integration in team science. American Journal of Preventative Medicine, 35(2 Suppl), S151-S160

Moran, J. (2002). Interdisciplinarity. London, England: Routledge.

National Academy of Sciences, National Academy of Engineering, and Institute of Medicine. (2005). Facilitating interdisciplinary research (p. 2), Washington, DC: National Academies Press.

National Research Council (NRC). (2003). BIO2010: Transforming undergraduate education for future research biologists. Washington, DC: National Academies Press.

NRC. (2009). A new biology for the 21st century. Washington, DC: National Academies Press.

NRC. (2015). Enhancing the effectiveness of team science. Washington, DC: National Academies Press.

Newell, W. H. (1990). Interdisciplinary curriculum. Issues in Integrative Studies, 8, 69-86

Newell, W. H., \& Green, W. J. (1982). Defining and teaching interdisciplinary studies. Improving College and University Teaching, 30(1), 23-30.

Öberg, G. (2009). Facilitating interdisciplinary work: Using quality assessment to create common ground. Higher Education, 57(4), 405-415.

Pellmar, T. C., \& Eisenberg, L. (2000). Bridging disciplines in the brain, behavioral, and clinical sciences. Washington, DC: National Academies Press.

Portland State University. (2019). Deliberative democracy. Retrieved February 25, 2019, from www.pdx.edu/stem/deliberative-democracy

President's Council of Advisors on Science and Technology. (2012). Engage to excel: Producing one million additional college graduates with degrees in science, technology, engineering, and mathematics. Washington, DC: U.S. Government Office of Science and Technology.

Redish, E. F., \& Cooke, T. J. (2013). Learning each other's ropes: Negotiating interdisciplinary authenticity. CBE-Life Sciences Education, 12(2), 175186.

Redish, E. F., \& Hammer, D. (2009). Reinventing college physics for biologists: Explicating an epistemological curriculum. American Journal of Physics, $77(7), 629-642$

Repko, A. F. (2008). Interdisciplinary research: Process and theory. Thousand Oaks, CA: Sage.

Rogers, Y., Scaife, M., \& Rizzo, A. (2005). Interdisciplinarity: An emergent or engineered process? In Derry, S. J., Schunn, C. D., \& Gernsbacher, M. A
(Eds.), Interdisciplinary collaboration: An emerging cognitive science (pp. 265-285). Mahwah, NJ: Erlbaum.

Rosenfield, P. L. (1992). The potential of transdisciplinary research for sustaining and extending linkages between the health and social sciences. Social Science \& Medicine, 35(11), 1343-1357.

Scott, T. D., Hazari, Z., Potvin, G., Sadler, P. M., \& Sonnert, G. (2014). Interdisciplinary affinity: Definitions and connections to physics identity. In Engelhardt, P. V., Churukian, A. D., \& Jones, D. L (Eds.), 2014 PERC Proceedings held July 30-31, 2014, in Minneapolis, MN.

Stokols, D., Harvey, R., Gress, J., Fuqua, J., \& Phillips, K. (2005). In vivo studies of transdisciplinary scientific collaboration: Lessons learned and implications for active living research. American Journal of Preventive Medicine, 28(2 Suppl 2), 202-213.

Stokols, D., Misra, S., Moser, R. P., Hall, K. L., \& Taylor, B. K. (2008). The ecology of team science. Understanding contextual influences on transdisciplinary collaboration. American Journal of Preventive Medicine, 35(2 Suppl), S96-S115.

Thompson, K. V., Chmielewski, J., Gaines, M. S., Hrycyna, C. A., \& LaCourse, W. R. (2013). Competency-based reforms of the undergraduate biology curriculum: Integrating the physical and biological sciences. CBE-Life Sciences Education, 12(2), 162-169

Vázquez Alonso, Á., Manassero Mas, M. A., García Carmona, A., \& Montesano de Talavera, M. (2016). Diagnosing conceptions about the epistemology of science: Contributions of a quantitative assessment methodology. In Asia-Pacific Forum on Science Learning and Teaching, 17(1), 1-28.

Watkins, J., Coffey, J. E., Redish, E. F., \& Cooke, T. J. (2012). Disciplinary authenticity: Enriching the reforms of introductory physics courses for life-science students. Physical Review Special Topics Physics Education Research, 8(1), 1-17.

Weber, C. F. (2016). Beyond the cell: Using multiscalar topics to bring interdisciplinarity into undergraduate cellular biology courses. CBE-Life Sciences Education, 15(2), es1.

Weingart, P. (2010). A short history of knowledge formations. In Frodeman, R., Klein, J. T., \& Pacheco, R. C. D. S. (Eds.), The Oxford handbook of interdisciplinarity (pp. 3-14). Oxford, UK: Oxford University Press.

Welch, J., IV. (2003). Future directions for interdisciplinary effectiveness in higher education. Issues in Integrative Studies, 21(21), 170-203.

Wiggins, G., \& McTighe, J. (1998). What is backward design? Understanding by Design, 1, 7-19.

Woodin, T., Vasaly, H., McBride, D., \& White, G. (2013). Integration of physics and biology: Synergistic undergraduate education for the 21st century. CBE-Life Sciences Education, 12(2), 120-123.

You, H. S., Marshall, J. A., \& Delgado, C. (2018). Assessing students' disciplinary and interdisciplinary understanding of global carbon cycling. Journal of Research in Science Teaching, 55(3), 377-398. 